\title{
Parental and Child Health Beliefs and Behavior
}

\author{
T.E. Dielman, Ph.D. \\ Sharon Leech, M.P.H. \\ Marshall H. Becker, Ph.D. \\ Irwin M. Rosenstock, Ph.D. \\ W.J. Horvath, Ph.D \\ The University of Michigan \\ Susan M. Radius, Ph.D. \\ Towson State University
}

ABSTRACT: Personal interviews concerning health beliefs and behaviors were conducted with a parent and child in each of 250 households. Index scores were constructed for parental and child health beliefs, and these scores were entered, along with demographic variables, in a series of multiple regression analyses predicting child health beliets and behaviors. The age of the child was the variable most highly associated with three of four child health behaviors and four of six child health beliefs. The children's snacking between meals and cigarette smoking were related to several parental behaviors and, to a lesser extent, parental health beliets. The children's health beliefs were less predictable than were their health behaviors, and the observed significant relationships were with parental health beliefs and demographics. The implications for the design of health education programs are discussed.

A number of investigators have reported positive correlations between the income and educational level of adults and their own health beliefs and behavior. ${ }^{1.5}$ Studies of factors related to preventive health behavior which parents practice on behalf of their children have, for the most part, been restricted to the analysis of sociodemographic differences associated with such behavior. Creen ${ }^{6}$ conducted a study of mothers' preventive health behavior

Dr. Dielman is Associated Professor and Ms. Leech is a Research Associate in the Department of Postgraduate Medicine. Dr. Horvath is Professor of Psychiatry. All are with The University of Michigan School of Medicine. Drs. Becker and Rosenstock are Professors in the Department of Health Behavior and Health Education. The University of Michigan School of Public Health. Dr. Radius is Assistant Professor, Department of Health Science, Towson State University. Reprints requests should be addressed to: Dr. T.E. Dielman, C-1210 Towsley, University of Michigan. Ann Arbor. Michigan 48109. This research was supported, in part, by Grant No. MH-32210 from the National Institute of Mental Health, Crant No. IP50-N502013 from the National Center for Health Services Research, and Grant No. 5K04-HDOO237 from the National institute of Child Health and Human Development. 
for their children. Immunizations, well baby visits, prenatal care, preventive dental care, and possession of fever thermometers and medical books were employed as preventive health behavior indices. Socioeconomic status was the background variable most highly correlated with preventive health behavior. Health knowledge and "planfulness" were also significantly and positively correlated with preventive health behavior. Becker, et al. ${ }^{7.8}$ and Maiman, et al. ${ }^{9}$ found mothers' health beliefs to be significantly related to preventive care visits for their children and to compliance with a dietary regimen prescribed for obese children.

Studies of the health attitudes and health behavior of young people have generally shown the same family socioeconomic relationships as have the studies of adult attitudes and behavior. In one such study, ${ }^{10}$ students' smoking habits were found to be significantly related to their parents' smoking habits, the father's occupation, and the students' school grades. The relationship between parental and children's smoking behavior has been borne out by several subsequent investigations, ${ }^{11} 110$ although the association to date has been stronger for adolescent males than for females.15.16

Efforts to compare the predictive power of parental health beliefs and behavior with respect to those of their children have been relatively rare. Tyroler, et al. ${ }^{17}$ provided evidence of withinfamily concordance of preventive health behavior with respect to an oral poliomyelitis vaccine program and the salvage of carious teeth. These results suggested maximal maternal influence on familial preventive health behavior.

Exploratory research by Gochman, $8 \cdot 21$ on the developmental aspects of perceptions of vulnerability to disease suggests that children are consistent in their perceptions of susceptibility to a variety of illnesses, accidents, and health problems. Relatively older children exhibited greater consistency between their perceptions of vulnerability to unspecified ill health conditions and in their estimates of vulnerability to specific illnesses. In a study of 108 children conducted at a summer camp, Gochman ${ }^{19}$ was also able to show that the relationship between children's perceptions of vulnerability to health problems and potential health behavior was influenced by both degree of perceived internal control and salience of health.

Lewis, et al. ${ }^{22}$ studied the health-related beliefs and expectations of over 300 children who were observed for two years as part of a larger project to evaluate a program permitting child-initiated use of school nursing services. Some of the constructs examined were "definition of health." "past experiences (with illness or injury)," "use of sick role," "locus of control," and such elements of the Health Beliefs Model as "perceived vulnerability (health status)," 
"perceived severity of illness/injury," "perceived benefits of care," and "knowledge/beliefs about health/disease." Results demonstrated that these constructs could be measured among the children studied, and also revealed that these health orientations were significantly altered by participation in the study.

Radius, et al. ${ }^{23.24}$ presented results from initial analyses of data obtained in a survey of children's health beliefs/behaviors. About half the children interviewed were not concerned about health matters (level of concern was independent of age and sex) and engaged in dysfunctional health behaviors. Dielman, et al. ${ }^{25}$ have factor analyzed items from the same survey which were designed to measure children's perceptions of the Health Belief Model constructs, such as vulnerability to and seriousness of disease. Six correlated factors emerged from that analysis: (1) Specific Health Concerns, (2) Ceneral Health Concerns, (3) Perceived Parental Concerns, (4) Perceived Ceneral Susceptibility, (5) Perceived Susceptibility to Specific Conditions, and (6) Perceived Seriousness of and Susceptibility to Disease. No significant sex differences or sex-byage interactions were found for any of the six factors. Younger children scored significantly higher on the Specific Health Concerns and Perceived General Susceptibility factors, while older children scored significantly higher on Perceived Parental Concern. There was a tendency for the variability in factor scores to be greater among younger children. In a related study, Leech, et al. ${ }^{26}$ reported the results of a factor analysis of adult health beliefs. This analysis resulted in five adult health belief constructs. The current report is based, in part, on the parent and child health belief factors identified in these two latter studies.

The purpose of the present investigation was to determine the relationships between the health beliefs and behaviors of parents and those of their children. A secondary issue was the determination of the variation in children's health beliefs and behaviors accounted for by those of their parents and independent of parental age and educational level.

\section{METHODS}

During April 1977, a sample was drawn for a household interview survey of health beliefs, health behaviors, and health status in Washtenaw County, Michigan. A sampling rate of $1 / 68$ resulted in a total of 1,239 households selected for study. The sampling was conducted on a multi-stage probability basis. ${ }^{27}$ Since several institutions for higher learning are located in the area, households were excluded from the study if the primary adult respondent was residing in the county primarily for the purpose of attending a college or university. This criterion resulted in the deletion of 130 , or $10.5 \%$, of the 1,239 households initially 
selected. Of the remaining 1,109 households, $109(9.8 \%)$ were refusals, and 146 $(13.2 \%)$ were other sources of non-response (not at home after repeated calls, house vacant, etc.); the remaining 854 households $(77.0 \%)$ yielded completed interviews.

At least one adult in each household was interviewed. The spouse of the primary respondent, when there was one, was also interviewed in a randomly selected one-half of the households. Of the 244 spouses of eligible respondents, there were 10 refusals $(4.1 \%)$ and 13 other reasons for non-response $(5.3 \%)$. Whenever there were children between 6 and 17 years of age in the family, one child was randomly selected for interviewing as well. Seven children $(2.7 \%)$ of the resulting sample of 264 refused to be interviewed, and another seven were not interviewed for other reasons (not at home after repeated calls, etc.), resulting in 250 completed interviews with the children. The higher interviewer success rate among spouses and children was presumably due to the fact that one household member (the primary respondent) had already been located and had been successfully interviewed.

All interviews were conducted in the household by trained interviewers. Interviewing time with the adults ranged from one-half hour to three hours, with an average of 90 minutes. Interviewing time with the children ranged from 15 to 55 minutes, with an average of 30 minutes. One hundred and twenty-four of the children were 6 to 11 years of age, the remaining 126 were 12 to 17 years old

\section{RESULTS AND DISCUSSION}

The first steps in the data analyses were to construct the adult and child health belief indices, using factor analysis. These procedures and the internal consistencies (alpha coefficients) of the indices are detailed in Dielman, et al. ${ }^{25.27}$ and Leech, et al. ${ }^{26}$ The distributions of scores on the adult and child health behavior indices are shown in Tables 1 and 2.

Following index construction, the parental health belief indices, health behavior indices and two parental demographic variables, education and age, were employed as predictor variables in a series of multiple regression analyses. The children's health belief and health behavior indices served as criteria. The full model $R^{2}$ values which resulted from the prediction of each criterion from the demographic predictors alone, parental health beliefs alone, and parental health behaviors alone, in addition to each pair of sets of predictors and all three sets in combination are presented in Table 3.

A review of Table 3 shows that child health behaviors are influenced by a variety of parental characteristics (except for parental beliefs) but that child health beliefs are scarcely influenced by parental characteristics.

Scanning the first column of Table 3 reveals that the parental demographic variables were significant predictors of child health behaviors, as well as the children's specific health concerns and 
TABLE 1

Child Health Behavior Indices

$(N=250)$

\begin{tabular}{|c|c|c|c|c|c|c|}
\hline & & $\begin{array}{c}\text { (1) } \\
\text { Current } \\
\text { Smoker }\end{array}$ & $\begin{array}{c}\text { (2) } \\
\text { Ever Tried } \\
\text { Smoking }\end{array}$ & $\begin{array}{c}\text { (3) } \\
\text { Never } \\
\text { Smoked }\end{array}$ & & Total \\
\hline \multirow[t]{2}{*}{ Cigarette Smoking } & $\begin{array}{l}N \\
\%\end{array}$ & $\begin{array}{l}19 \\
7.5\end{array}$ & $\begin{array}{c}54 \\
21.5\end{array}$ & $\begin{array}{l}177 \\
71.0\end{array}$ & & $\begin{array}{c}250 \\
100.0\end{array}$ \\
\hline & & $\begin{array}{l}\text { (1) } \\
\text { Every } \\
\text { Day }\end{array}$ & $\begin{array}{c}(2) \\
\text { Most } \\
\text { Days }\end{array}$ & $\begin{array}{l}(3) \\
\text { Once in } \\
\text { a While }\end{array}$ & $\begin{array}{c}\text { (4) } \\
\text { Never }\end{array}$ & Total \\
\hline \multirow[t]{2}{*}{ Snacking } & $\begin{array}{l}N \\
\%\end{array}$ & $\begin{array}{c}75 \\
30.0\end{array}$ & $\begin{array}{c}88 \\
35.8\end{array}$ & $\begin{array}{c}79 \\
31.8\end{array}$ & $\begin{array}{c}8 \\
3.2\end{array}$ & $\begin{array}{l}250 \\
100.0\end{array}$ \\
\hline & & $\begin{array}{c}(1) \\
\text { Never }\end{array}$ & $\begin{array}{l}\text { (2) } \\
\text { Ever }\end{array}$ & $\begin{array}{c}(3) \\
\text { In Past } \\
\text { Year }\end{array}$ & $\begin{array}{l}\text { Missing } \\
\text { Data }\end{array}$ & Total \\
\hline \multirow[t]{2}{*}{$\begin{array}{l}\text { Teeth Cleaning } \\
\text { (at dentist) }\end{array}$} & $\begin{array}{l}N \\
\%\end{array}$ & $\begin{array}{c}36 \\
14.9\end{array}$ & $\begin{array}{c}78 \\
32.2\end{array}$ & $\begin{array}{l}128 \\
52.9\end{array}$ & $\frac{8}{-}$ & $\begin{array}{c}250 \\
100.0\end{array}$ \\
\hline & & $\begin{array}{c}(1) \\
\text { Never }\end{array}$ & $\begin{array}{c}(2) \\
\text { Once in } \\
\text { a While }\end{array}$ & $\begin{array}{l}(3) \\
\text { Most } \\
\text { Days }\end{array}$ & $\begin{array}{l}\text { (4) } \\
\text { Every } \\
\text { Day }\end{array}$ & Total \\
\hline $\begin{array}{l}\text { Breakfast } \\
\text { Frequency }\end{array}$ & $\begin{array}{l}N \\
\%\end{array}$ & $\begin{array}{l}10 \\
4.0\end{array}$ & $\begin{array}{c}45 \\
18.0\end{array}$ & $\begin{array}{c}49 \\
19.6\end{array}$ & $\begin{array}{l}146 \\
584\end{array}$ & $\begin{array}{c}250 \\
100.0\end{array}$ \\
\hline
\end{tabular}

perception of their susceptibility to specific illnesses. The details of the specific associations in these and subsequent full model analyses will be discussed in connection with the results of the stepwise multiple regression analyses. With respect to parental health beliefs as predictors of the children's health beliefs and behaviors (column two of Table 3), the only criterion which showed a significant $R^{2}$ was the children's perception of seriousness of and susceptibility to disease. Skipping to column four of Table 3 , it can be seen that the combination of parental demographics and health beliefs resulted in $R^{2}$ values which were, in practically every case, an additive combination of the two separate sets of predictors. Combination of the two sets resulted in an increase of two percent over the use of the demographic variables alone in the criterion variance accounted for in the children's perception of susceptibility to specific illnesses ( $F=1.04$, n.s.) and of six percent in the case of perceptions of seriousness and susceptibility $(F=3.15, p<.01)$. In both cases the total criterion variance accounted for was signifi- 


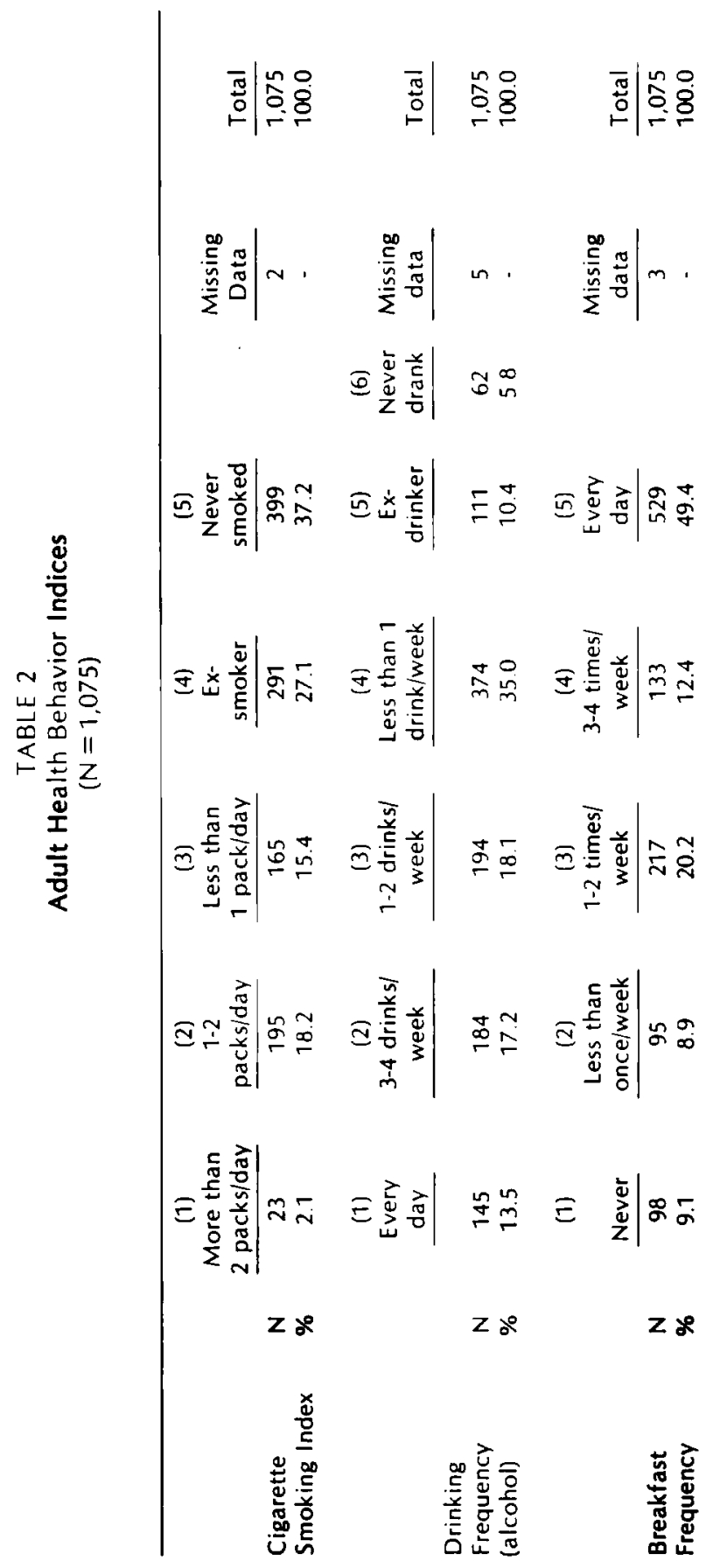


丞|

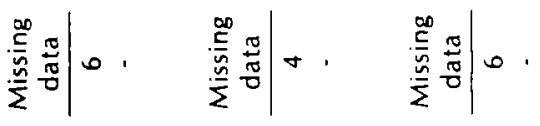

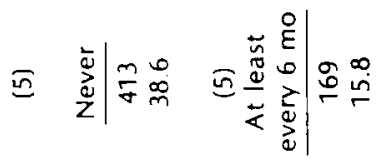

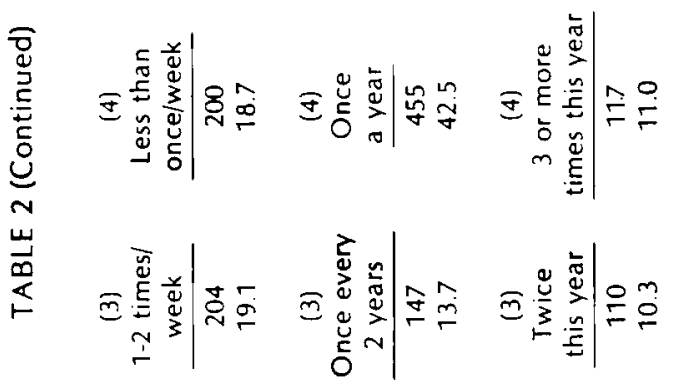

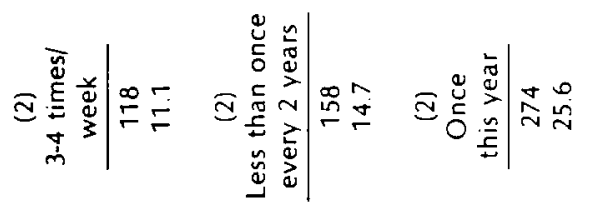

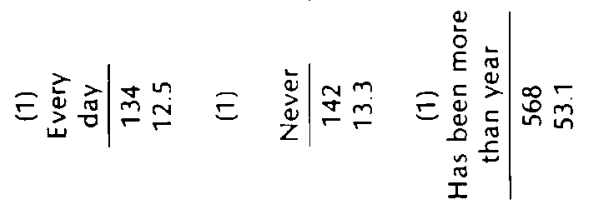

$z$ z $z$ z

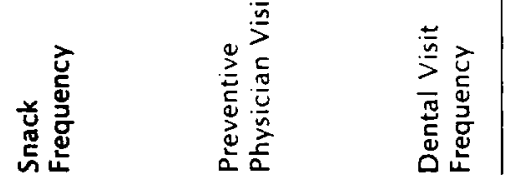




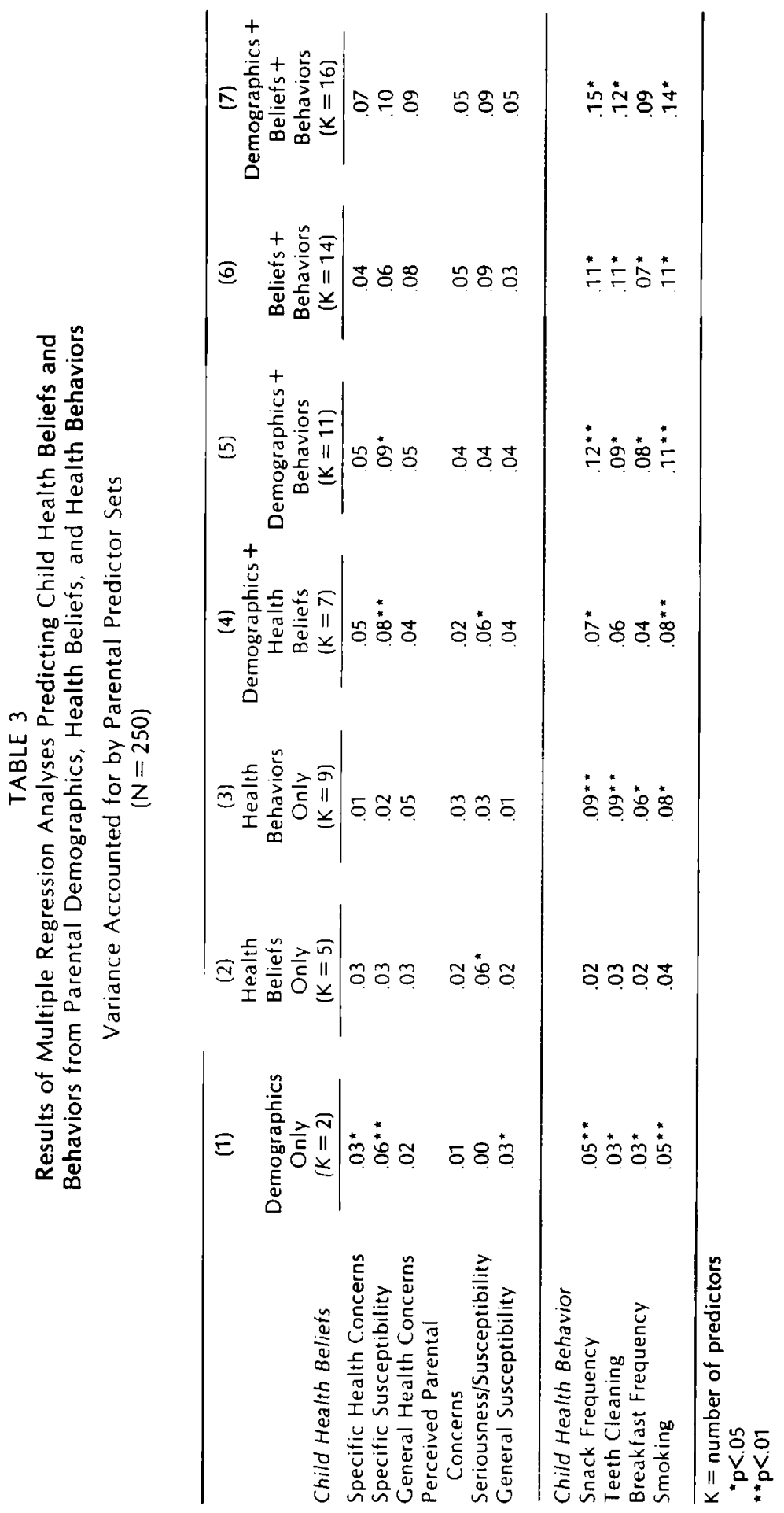


cant at or beyond the 05 level. In the case of the child health behaviors, the combination of the two sets of predictors resulted in non-significant increases in the criterion variance accounted for and in a decrease in the significance level of the full set of predictors in the case of the children's teeth cleaning and breakfast frequency. The parents' health behaviors, (column three of Table 3) considered as a set, proved to be significant predictors of the four specific children's health behaviors but not of the children's health beliefs. The combination of parental demographics and health behavior (column five of Table 3 ) reached significance in the prediction of all of the children's health behaviors as well as the children's perceptions of their susceptibility to specific diseases. The combination of parental health beliefs and behaviors (column six of Table 3 ) resulted in no significant increases in the variance accounted for in the child health beliefs and behaviors beyond that accounted for by parental behaviors alone. The variance accounted for in child health behaviors, but not child health beliefs, was significantly greater than that accounted for by parental health beliefs alone. The $R^{2}$ values resulting from the prediction of child health beliefs from parental beliefs and behaviors combined were not significant. The $\mathrm{R}^{2}$ values in the prediction of child health behaviors were significant except for breakfast frequency. Combining all three sets of parental predictors (column seven of Table 3 ) resulted in a significant full-model $R^{2}$ in the prediction of the children's snack frequency, teeth cleaning, and cigarette smoking.

The full-model prediction equations in Table 3 which reached at least the .05 level of significance are summarized in greater detail in Table 4. Shown in Table 4 are the predictor variables from each model which made significant independent contributions to the criterion variance. Also shown are the associated F-ratios and probability level for each entry, and the zero-order correlations between each significant predictor and the criterion.

In the interpretation of the zero-order relationships in Table 4, it should be borne in mind that both the children's and parents' health behavior variables were coded in a manner such that a higher score indicated positive health habits (See Tables 1 and 2). For example, the more frequently a child snacked between meals, the lower his score on "Child's Snacking," so that the negative correlation between parent's age and child's snacking indicates that younger parents tend to have children who score higher on the "child's snacking" variable, i.e., have children who snack less. The positive correlation between parents' education and child's teeth cleaning indicates that the children of more educated parents visit the dentist to have their teeth cleaned more frequently. Similarly, 


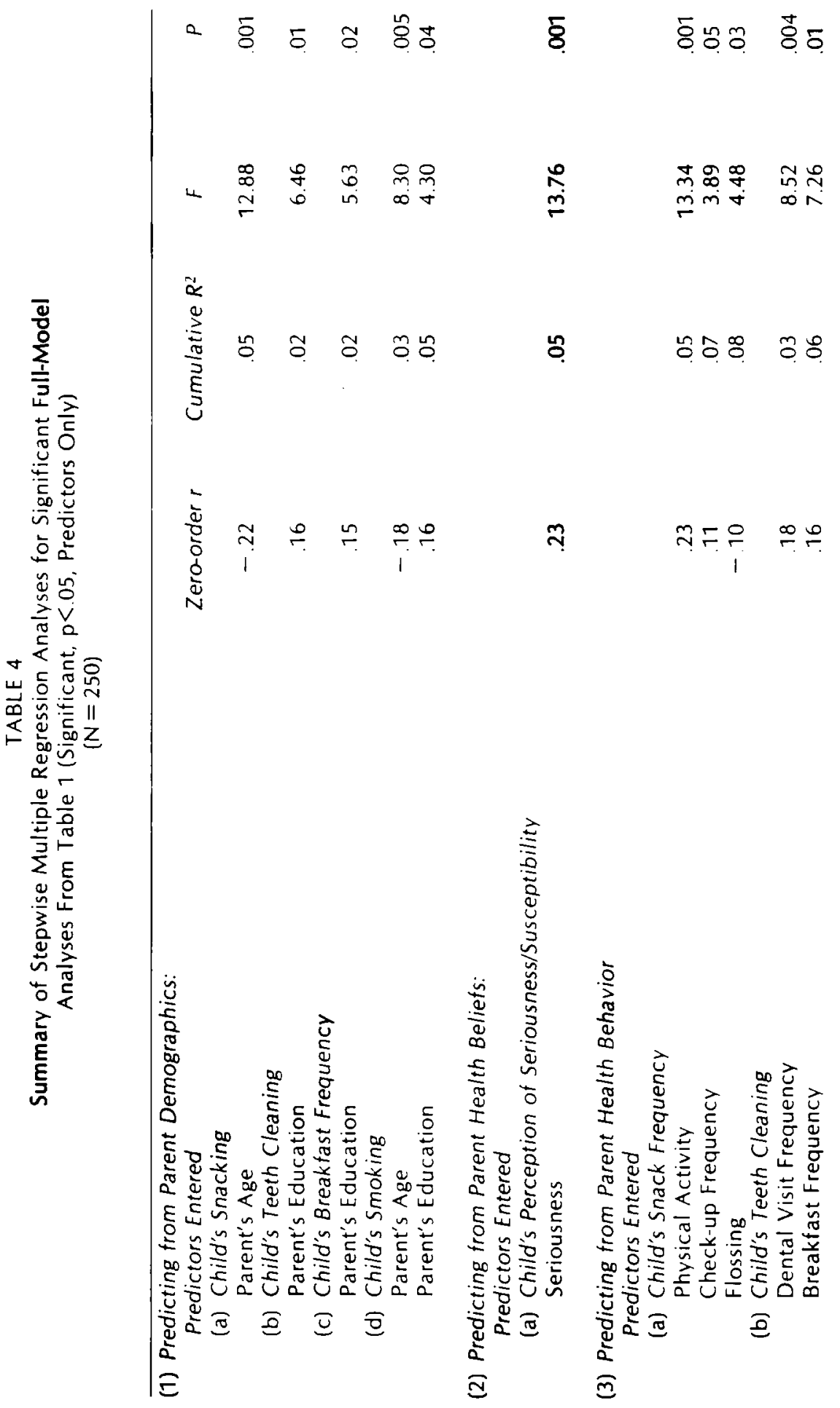




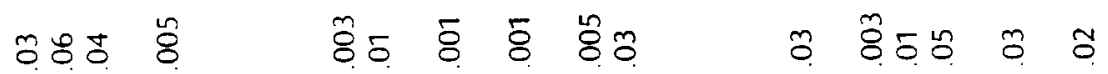

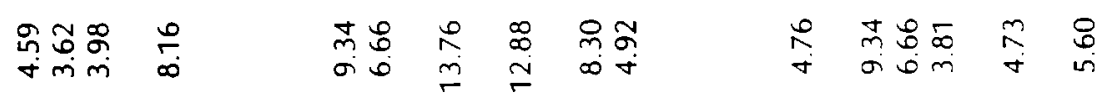

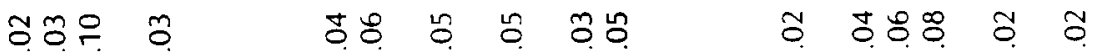

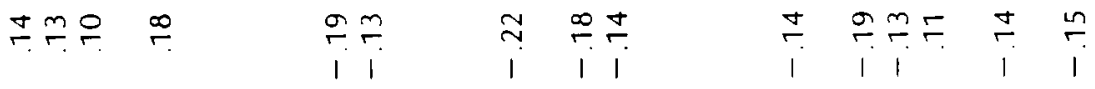

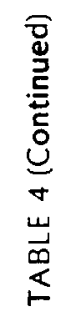

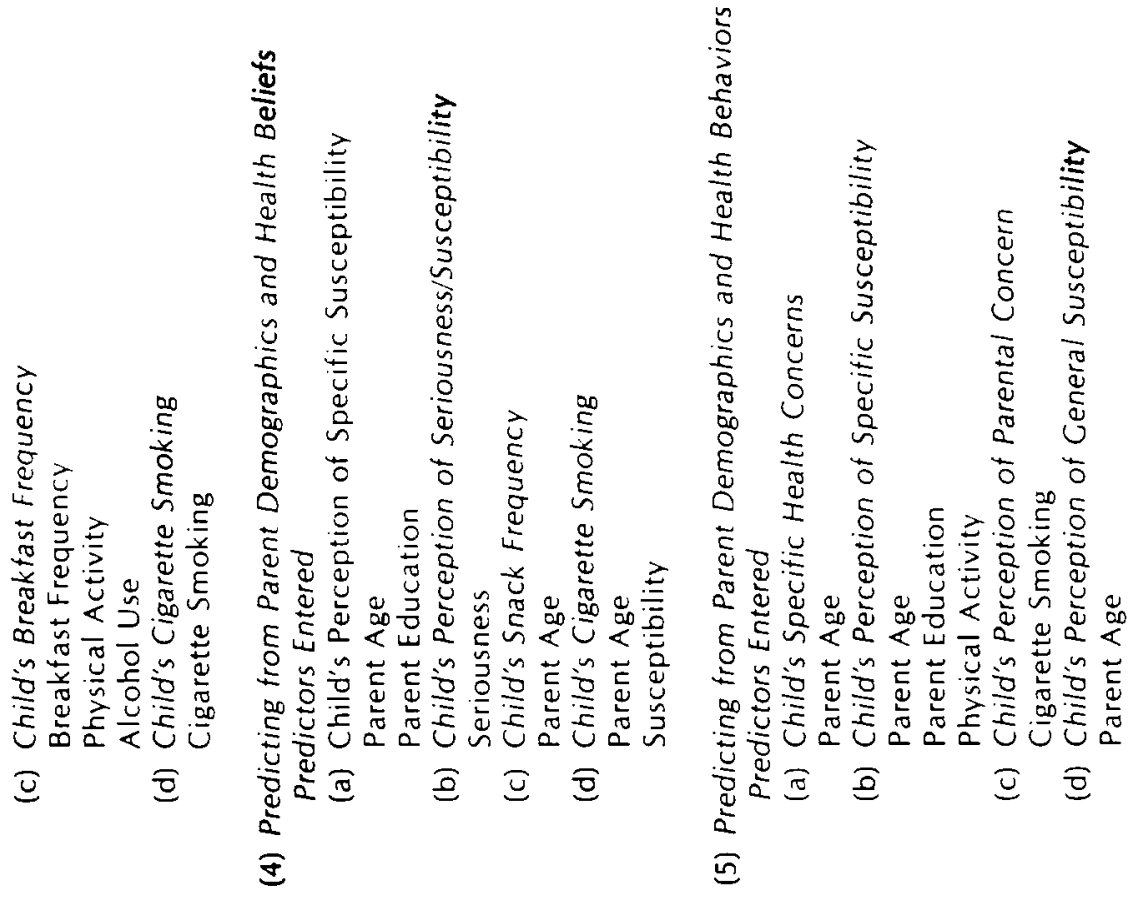




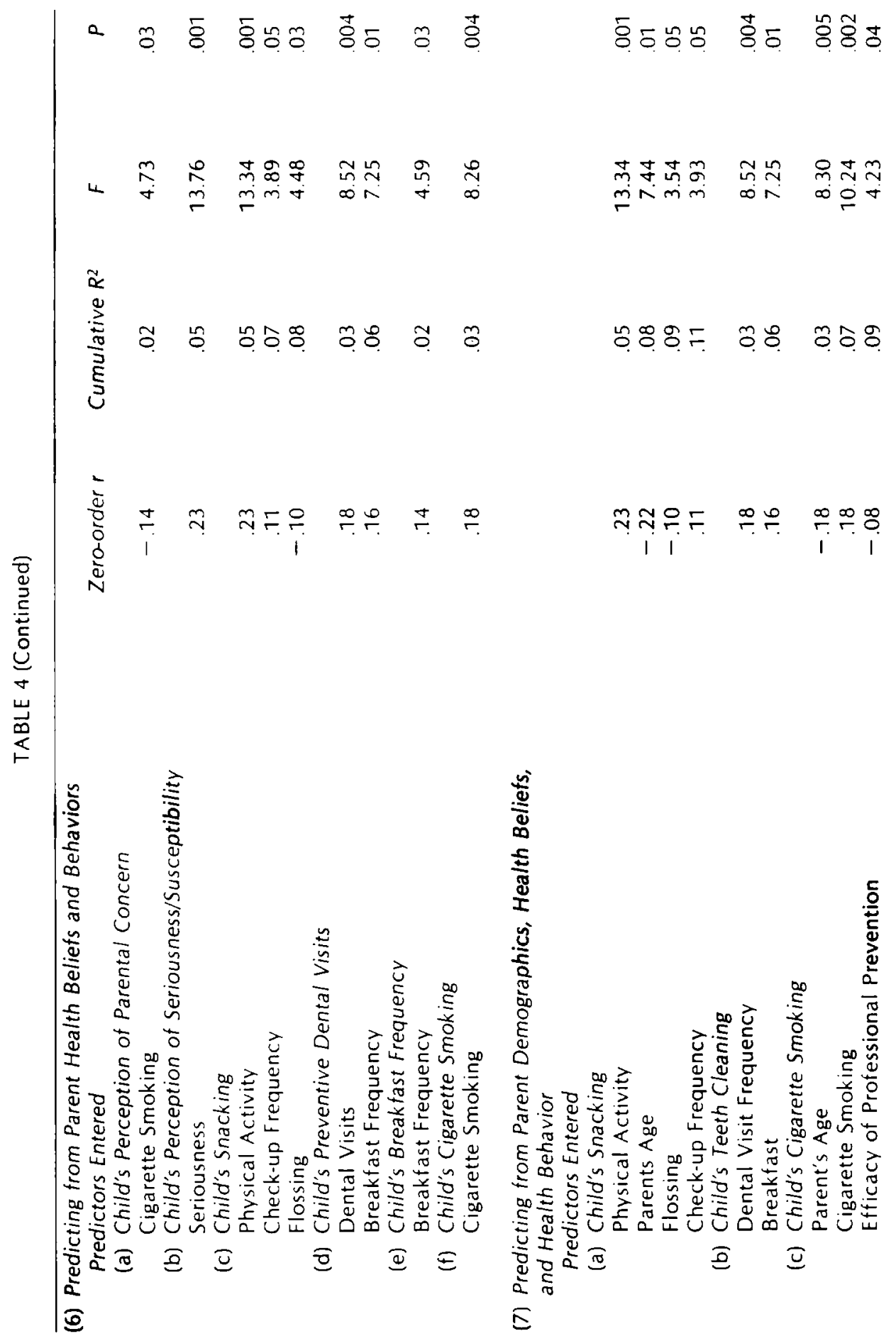


result $1 \mathrm{c}$ in Table 4 means that the children of more educated parents tend to have breakfast more frequently. The only child health behavior which was related to both the age and education of the parent was cigarette smoking, which tended to be more manifest among chldren of older and less educated parents.

Among demographic factors, parental age emerged as the most consistent predictor of children's health beliefs. Age of the parent was the only significant predictor of the children's specific health concerns and perception of general susceptibility to illness, and was the variable most highly related to the children's perception of susceptibility to specific illnesses. Age of the parent was negatively related to the children's health beliefs in each instance, indicating that younger parents have children who regard themselves as more susceptible to specific illnesses and illness in general and have more specific health concerns. These results are confounded with the age of the child inasmuch as the ages of the parents and children are correlated. This observation is supported by the fact that age differences, in the same direction on these three factors, were found in the analyses of the children's factor scores reported by Dielman, et $\mathrm{al}^{25}$. The relative importance of the parent's and child's age was tested in these instances by adding the age of the child to the full model regression equations. In each instance, the age of the child emerged as the most significant predictor and parental age no longer accounted for a significant, independent proportion of the criterion variance. In the prediction of children's specific health concerns, age of the child correlated significantly with the criterion $(p<.001)$, and parental perceptions of susceptibility to disease was the only other significant predictor

When predicting children's perceptions of susceptibility to specific diseases, the child's age correlated -.35 ( $p<.001)$, with the criterion, followed by parental education ( $r=-.13$, cumulative $\left.\mathrm{R}^{2}=.15, p<.01\right)$ and parental physical activity level $(r=.11$, cumulative $\mathrm{R}^{2}=.17, \mathrm{p}<.05$ ). Age of the child correlated -.37 with children's perception of susceptibility to disease in general, followed by parental perceptions of susceptibility to disease $\left(r=.09\right.$, cumulative $\left.R^{2}=.15, p<.05\right)$

Two additional parental variables entered as significant predictors of the child's perception of susceptibility to specific illnesses: parent's educational level and level of physical activity. The remaining three children's health belief indices did not receive significant, independent contributions from either of the parental demographic variables. The only parental variable accounting for a significant, independent proportion of the variance in the children's perception of parental concern about the child's health was the extent to which the parent smoked. The parents who had chil- 
dren who perceived them as being more concerned tended to be heavier smokers. This interlocks with two additional findings: 1) there is a positive association between the smoking habits of parents and their children, and 2) children who smoke tend to perceive their parents as being more concerned about their (the child's) health than do children who do not smoke. It follows, then, that the children of parents who smoke would tend to perceive their parents as being more concerned.

Parental age was also a significant predictor of two of the children's health behaviors - snacking and cigarette smoking - both of which increased with the age of the parent. As in the case of children's health beliefs, this relationship is largely attributable to the age of the child. When the child's age was added to the multiple regression equations in these two instances, the child's age emerged as the primary predictor. In the case of snacking frequency, the correlation with age of the child was -.25 , indicating that older children tend to snack more. Three additional predictors made significant, independent contributions to the criterion variance: parental physical activity $\left(r=.23\right.$, cumulative $R^{2}=.10$, $p<.01)$, parental dental flossing $\left(r=-.10\right.$, cumulative $R^{2}=.11$, $p<.05)$, and parental medical checkups $(r=.11$, cumulative $\mathrm{R}^{2}=.13, \mathrm{p}<.05$ ). The child's cigarette smoking correlated -.42 with the age of the child $(p<.001)$, indicating an increase of cigarette smoking among older children. Also entering this equation were parental cigarette smoking $\left(r=.18\right.$, cumulative $R^{2}=.20$, $p<.01$ ), parental perceptions of the efficacy of professional prevention ( $r=-.08$, cumulative $R^{2}=.22, p<.05$ ), and parental medical checkups $\left(r=.09\right.$, cumulative $\left.R^{2}=.23, p<.05\right)$. Going one step further and adding the children's estimates of the number of their peers who smoke cigarettes to the prediction equation resulted in accounting for 27 percent of the variance in the child's smoking behavior. Two predictors made completely independent and significant contributions: the number of peers the child had who were smokers $(r=.49, p<.001)$ and whether or not the child's parents smoked $(r=.18, p<.01)$.

Parental health behaviors were the primary predictors of children's health behavior, but no one variable emerged as a consistent predictor across all four children's health behavior indices. The parents of children who snacked less appeared to be more health-conscious, engaging in a greater degree of physical activity and having physical examinations more frequently. The one parental predictor which is inconsistent with this image is that parents of children who snacked less tended to floss less frequently. The results with respect to children's preventive dental hygienist visits were consistent. If the parents made such visits more frequently 
their children also made more frequent visits. These parents also tended to breakfast more frequently. (The parents of children who breakfasted more frequently, however, did not tend to do so.) Other than a higher educational level, the only parental characteristic associated with the child's breakfast frequency was a tendency to consume alcoholic beverages less frequently. The single child health behavior variable which was predicted by one of the parental health beliefs was cigarette smoking, for which the parents' belief in the efficacy of professional prevention was a significant predictor, entering the equation after parental age and cigarette smoking.

In each multiple regression model presented in Table 4 in which more than one predictor made a significant, independent contribution to the criterion variance accounted for, the significance of the interaction between predictors was tested by adding the interaction terms to the linear models. None of the interactive models accounted for a significantly greater proportion of criterion variance than did the linear models.

\section{CONCLUSIONS}

Viewed in the context of the predictive model employed in the current study, the children's health behaviors can, for the most part, be regarded as primarily developmental phenomena, some of which are linked in a general fashion to the global pattern of parental health behavior. A similar generalization may be made concerning children's health beliefs, except that here the beliefs of the parent need to be taken into account as well. The age of the child was the predictor which was most highly correlated with three of the four child behaviors and with four of the six child beliefs which were employed as criteria. None of the other variables which were employed as predictors were related to more than two of the children's health beliefs or behaviors. The children's snacking behavior was multiply determined, increasing with the age of the child but also related to a complex of parental health behavior variables. The cigarette smoking behavior of the children exhibited a similar complex of relationships, being associated with the child's age, parental behaviors of physical examinations and cigarette smoking, and the parental belief regarding the efficacy of professional preventive efforts. Addition of the smoking behavior of the children's peers to the model, however, overpowered all but parental smoking behavior in the prediction of the children's smoking. It must be recognized, however, that the number of peers who smoke may be a function of the friends one chooses after beginning to smoke cigarettes, rather than being a determinant of smoking 
behavior. The frequency of children's preventive dental visits and breakfasting were more isolated forms of behavior in the predictive model. Both were predicted by parental breakfast frequency. The children's preventive dental visits were additionally related to parental dental visits, and the children's breakfast fequency was related to the age of the child.

These results suggest that at least two areas of children's preventive health behavior-cigarette smoking and snacking between meals - are subject to influence by parental health behavior and, to a lesser extent, parental health beliefs. Parental health beliefs are very likely a more distal influence in that they operate via their influence on parental behavior, more than by direct communication to the child. Parental behavior is more pervasive and visible on a daily basis, while their beliefs concerning health are seldom communicated verbally. Whether parental health education programs would be an effective means of transmitting preventive health habits to their children is quite another question. The first problem would lie in achieving behavioral change among those parents whose health habits were less than ideal. It may be that a more effective way to approach the problem would be through behaviorally oriented preventive health programs among children, such as those which have been undertaken by Evans, et al., ${ }^{28}$ McAllister, et al., ${ }^{29}$ and Perry, et al. ${ }^{30}$ These programs have been shown to be effective, at least over short-term (three years) periods in reducing the onset of cigarette smoking among junior high school students. It should be kept in mind, however, that even behaviorally oriented programs directed toward children should have a sound cognitive component. Knowledge and beliefs as well as reinforced skills should be emphasized. The question of whether the behavior and attitudes of the children may ultimately be effective in achieving some measure of behavioral change among their parents has yet to be addressed.

Also not addressed here are two possible grounds for emphasizing parental health beliefs which are not directly related to the motivational or incentive effects of those beliefs on their children. In the narrow sense, we cannot ethically work to modify children's health beliefs and behavior without the informed consent of their parents and that is more likely to be obtained if the parents hold beliefs that accord with the purpose of the behaviors being taught. More broadly, however, the goals of health education are not restricted to behavioral modifications of narrow scope. We generally wish to educate for new orientations to health and illness, as well as accomplishing a specific programmatic goal. Accordingly, we may wish to teach a set of health beliefs that will undergird future health programs as well as present ones. 


\section{REFERENCES}

1. Coburn D, Pope CR: Socioeconomic status and preventive health behavior. I Health Soc Behav 15:67-68, 1974 .

2. May JT: Health status, health action and psycho-social indicators: In the bend of the Cumberland, part II: A survey of health in lower income areas of Nashville. Nashville, Tennessee, Evaluation, Survey, and Health Research Corporation, 1973.

3. May IT. Sprague H. Thomas L: Family health indicators: In the bend of the Cumberland Nashville, Tennessee, Evaluation, Survey, and Health Research Corporation, 1974.

4. Belloc NB. Breslow L: Relationship of physical health status and health practices: Prev Med 1:409-421, 1972

5. Hochstim |R: Conceptual and methodological problems in developing a measure of health status. Berkeley, Human Population Laboratory, California Department of Public Health. 1969.

6. Green LW: Status identity and preventive health behavior Pacific Health Educ Rep 1:1-130, 1979.

7. Becker MH. Maiman LA, Kirscht JP. Haefner DP. Drachman RH: The health belief model and prediction of dietary compliance A field experiment. I Health Soc Behav 18:348-366, 1977

8. Becker MH. Nathanson CA, Drachman RH, Kirscht JP: Mothers' health beliefs and children's clinic visits: A prospective study. I Commun Health 3:125-135, 1977.

9 Maiman LA, Becker MH, Kirscht JP, Haefner DP. Drachman RH: Scales for measuring health belief model dimensions: A test of predictive value, internal consistency, and relationships among beliefs Health Educ Mongr 5:215-230, 1977.

10 Salber EK, Ablein T: Smoking behavior of Newton School children-5-year follow-up. Pediatrics 40:363-372, 1967.

11. National Institute of Health: Teenage smoking, national patterns of cigarette smoking, age 12 through 18, in 1972 and 1974. U.S. Department of Health, Education, and Welfare, Public Health Service, National Institutes of Health, DHEW Publication No.(NIH) 76-931, 1976

12. Merki DI, Creswell WH, Stone DB, Huffman W. Newman I: The effects of two educational methods and message themes on rural youth smoking behavior. I Sch Health 38:448-454, 1968

13. Borland BL, Rudolph JP: Relative effects of low socio-economic status, parental smoking and poor scholastic performance on smoking among high school students. Soc Sci Med 9:27-30, 1975.

14. Palmer AB. Some variables contributing to the onset of cigarette smoking among junior high school students. Soc Sci Med 4:359-366, 1979

15. Wohlford $P$ : Initiation of cigarette smoking: Is it related to parental behavior? I Consult Clin Psychol 34:148-151, 1970

16. National Cancer Institute, American Cancer Society. Cigarette smoking among teenagers and young women. U S. Department of Health, Education, and Welfare, Public Health Service, National Institutes of Health, National Cancer Institute, DHEW Publication No (NIH) 77-1203, 1976

17 Tyroler HA, Johnson AL. Fulton JT. Patterns of preventive health behavior in populations. I Health Hum Behav 6:127-140, 1965

18. Cochman DS: Children's perceptions of vulnerability to illness and accidents. Public Health Rep 85:69-73, 1970.

19. Gochman DS: Development of health beliefs. Psychol Rep 31:259-266, 1972.

20. Gochman DS: The organizing role of motivation in health beliefs and intentions. I Health Soc Behav 13:285-293, 1972.

21. Cochman DS, Bagramian RA. Sheiham A: Consistency in children's perceptions of vulnerability to health problems. HSMHA Health Rep 87:282-288, 1972.

22. Lewis CE, Lewis MA, Lorimer A, Palmer BB; Child-initiated care: The use of school nursing services by children in an "adult-free" system. Pediatrics 60:499-507, 1977.

23. Radius SM, et al.: Dysfunctional health behaviors and health beliefs of the school-aged child. Paper presented at the American Public Health Association, School Health Section, Los Angeles, California, 1978 
24. Radius SM, et al.: Adolescent perspectives on health and illness Adolescence 15:375-384, 1980.

25 Dielman TE, Leech SL, Becker MH, Rosenstock IM, Horvath WJ, Radius SM: Dimensions of children's health beliefs. Health Educ Quart 7:219-238, 1980.

26. Leech SL, Dielman TE, Rosenstock IM, Horvath WI: Dimensions of adult health beliefs. Tech Memo \#81.3. Dept of Postgrad Med. Ann Arbor. University of Michigan, 1981.

27. Dielman TE, Leech SL: Intrafamilial correlations among health beliefs and behaviors. Tech Memo \#81 5. Dept of Postgrad Med, Ann Arbor, University of Michigan, 1981.

28. Evans RI, Rozelle RM, Mittlemark MB, Hansen WB, Bane AL, Haris J: Deterring the onset of smoking in children: Knowledge of immediate physiological effects and coping with peer pressure, media pressure, and parent modelling. / App/ Soc Psychol 8:126-135. 1978.

29. McAllister A, Perry C, and Maccoby N: Pilot study of smoking, alcohol and drug abuse prevention Am / Pub Health 70:719-732, 1980.

30. Perry C. Killen I, Telch M. Slindard LA, and Danaher BC: Modifying smoking behavior of teenagers: A school-based intervention. Am / Pub Health 70:722-725, 1980. 